\title{
An Update on Grading of Salivary Gland Carcinomas
}

\author{
Raja R. Seethala
}

Received: 19 December 2008/ Accepted: 18 January 2009/Published online: 25 February 2009

(c) Humana 2009

\begin{abstract}
Histologic grade is a significant predictor of outcome in salivary gland carcinomas. However, the sheer variety of tumor type and the rarity of these tumors pose challenges to devising highly predictive grading schemes. As our knowledge base has evolved, it is clear that carcinoma ex pleomorphic adenoma is not automatically a high grade tumor as is traditionally suggested. These tumors should be further qualified as to type/grade of carcinoma and extent, since intracapsular and minimally invasive carcinomas ex pleomorphic adenoma behave favorably. The two carcinoma types for which grading schemes are common include adenoid cystic carcinoma and mucoepidermoid carcinoma. Adenoid cystic carcinomas are graded based solely on pattern with solid components portending a worse prognosis. Occasionally, adenoid cystic carcinomas may undergo transformation to pleomorphic high grade carcinomas. This feature confers a high propensity for lymph node metastasis and should thus be reported to alert the clinical team. Mucoepidermoid carcinomas are graded in a three tier fashion based on a constellation of features including cystic component, border, mitoses, anaplasia, and perineural invasion among others. All grading schemes are somewhat cumbersome, intimidating and occasionally ambiguous, but evidence suggests that using a scheme consistently shows greater reproducibility than using an intuitive approach. The intermediate grade category demonstrates the most variability between grading systems and thus the most controversy in management. In the AFIP system intermediate grade tumors cluster with high grade
\end{abstract}

\section{R. R. Seethala $(\square)$}

Department of Pathology and Laboratory Medicine, University of Pittsburgh Medical Center, A616.3 PUH, 200 Lothrop St, Pittsburgh, PA 15213, USA

e-mail: seethalarr@upmc.edu tumors, while in the Brandwein system, they cluster with low grade tumors.

Keywords Grading - Salivary carcinoma . Mucoepidermoid carcinoma - Adenoid cystic carcinoma . High grade transformation .

Carcinoma ex pleomorphic adenoma

\section{Introduction}

Salivary gland carcinomas comprise only $3-5 \%$ of all head and neck malignancies, yet they are the most diverse with at least 24 different types recognized by the World Health Organization (WHO) [1]. This diversity combined with the rarity of many of the tumor types and the unpredictability in long-term outcome impose a significant challenge on the management of salivary gland malignancies overall [2]. For prognosis and treatment, despite these aforementioned factors, it is critical to resolve these tumors, using both clinical and pathologic parameters, into therapeutically meaningful categories (Table 1) [3].

A review of numerous retrospective studies [4] indicates that histologic tumor grade ranks highly among the most important predictors of outcome for salivary gland carcinomas. High grade salivary carcinomas have a 5 year survival of roughly $40 \%$ while low and intermediate grade tumors have a 5 year survival of 85-90\% [2, 4]. In sizeable series, histologic grade is an independent predictor of outcome in multivariate analysis, but it also tends to correlate with other adverse prognosticators such as size and nodal status. However, the current approach to grading of salivary gland tumors is subject to many deficiencies and challenges that on a case by case basis may not always accurately predict outcome. Here I review current 
Table 1 General categories of management of primary salivary gland carcinomas [3]

\begin{tabular}{|c|c|c|c|}
\hline Surgery alone & Surgery and radiotherapy & Additional neck dissection & Systemic chemotherapy \\
\hline Negative margins & Close $(<2 \mathrm{~mm})$ or positive margins & $\begin{array}{l}\text { All cN+ } \\
\text { cN0 but high grade histology }\end{array}$ & $\begin{array}{l}\text { Metastatic or unresectable } \\
\text { disease }\end{array}$ \\
\hline Low grade histology & High grade histology & $\begin{array}{l}\text { cN0 but high risk (angioinvasive) } \\
\text { histologic subtype }\end{array}$ & \\
\hline $\begin{array}{l}\text { Low risk (non angioinvasive, } \\
\text { non infiltrative) histologic } \\
\text { subtype }\end{array}$ & $\begin{array}{l}\text { High risk (highly infiltrative) } \\
\text { histologic subtype }\end{array}$ & cN0 but high $\mathrm{T}$ stage (T3 or T4) & \\
\hline Low $\mathrm{T}$ stage $(\mathrm{T} 1$ or $\mathrm{T} 2)$ & $\begin{array}{l}\text { High T stage (T3 or T4) } \\
\text { pN+ } \\
\text { Perineural invasion }^{\mathrm{a}}\end{array}$ & & \\
\hline
\end{tabular}

$\mathrm{T}=$ tumor stage in TNM classification, $\mathrm{cN}+=$ clinically node positive, $\mathrm{cN} 0=$ clinically node negative, $\mathrm{pN}+=$ pathologically node positive

${ }^{a}$ Somewhat controversial depending on tumor type

histologic grading as applied to salivary gland carcinomas in general and with respect to select common tumor types.

\section{Discussion}

\section{General Grading of Salivary Gland Carcinomas}

The ideal requirements for any grading system are as follows:

- Accurately predicts outcome

- Can be used to stratify patients into distinct management categories

- Applicable to all sites in which a tumor can be seen

- Simple criteria

- Quick and time efficient

- Reproducible with minimal inter and intraobserver variability.

Practically speaking, this ideal is difficult or even impossible to achieve in salivary gland carcinomas mainly because of the lack of sufficient sample size to devise statistically valid systems that fulfill the aforementioned criteria. Meta analyses hold very little meaning since grading of salivary gland carcinomas is not standardized. Most grading is done 'intuitively' using general cytomorphologic features (pleomorphism, mitoses, necrosis) and is thus highly individualized. Even when grading systems exist, there may be several to address the same tumor type, none of which correlate exactly with one another.

Despite these obstacles, using the data available, as well as good clinical acumen, the various tumor types can at least be stratified into a meaningful working stratification scheme that can be used to parse tumors into those that do not require treatment beyond excision (i.e. low risk) of primary tumor and those that do (i.e. high risk). Table 2 divides all entities listed in WHO classification scheme into low risk and high risk categories. Histologic grading will additionally split certain tumor types (i.e. mucoepidermoid carcinoma) between both risk categories.

Is grading of salivary gland tumors always necessary? The answer is no. Many tumor types are for the most part definitionally high risk both histologically and biologically (i.e. conventional salivary duct carcinoma, squamous cell carcinoma, small cell neuroendocrine carcinoma) or low risk (i.e. epithelial-myoepithelial carcinoma, polymorphous low grade adenocarcinoma). The caveat is that high grade versions of 'intrinsically' low grade tumors do exist as do low grade versions of typically high grade tumors. Both pathologists and clinicians need to be aware of these variants. Thus:

- The usual example of such a tumor type may not need to be qualified with a grading descriptor.

- An unusually high or low grade variant of a tumor should be conveyed in the pathologic report.

Perhaps the most relevant example of this phenomenon is with carcinoma ex pleomorphic adenoma. Historically and even currently in the clinical literature, [2-4] carcinoma ex pleomorphic adenoma is automatically considered a high grade malignancy. In most cases, this is true with high grade adenocarcinoma, not otherwise specified (NOS), and salivary duct carcinoma being the most common histologic subtype of the carcinomatous component. However, as many as $15 \%$ of tumors are low grade and may behave in a more indolent fashion [5]. More recently, there is evidence to suggest that 'intracapsular' carcinoma ex pleomorphic adenoma and minimally invasive carcinoma $(<1.5 \mathrm{~mm}$ of invasion) ex pleomorphic adenoma (Fig. 1) are also indolent variants that should not be considered equivalent to the typical carcinoma ex pleomorphic adenoma. 
Table 2 Risk stratification of WHO [1] recognized salivary gland malignancies

\begin{tabular}{ll}
\hline Low risk & High Risk \\
\hline Acinic cell carcinoma & Sebaceous carcinoma and lymphadenocarcinoma \\
Low grade mucoepidermoid carcinoma ${ }^{\mathrm{a}}$ & $\begin{array}{l}\text { High grade mucoepidermoid carcinoma } \\
\text { a }\end{array}$ \\
Epithelial-myoepithelial carcinoma & Adenoid cystic carcinoma $^{\mathrm{b}}$ \\
Polymorphous low grade adenocarcinoma & Mucinous adenocarcinoma \\
Clear cell carcinoma & Squamous cell carcinoma \\
Basal cell adenocarcinoma & Small cell carcinoma \\
Low grade salivary duct carcinoma (low grade cribriform cystadenocarcinoma) & Large cell carcinoma \\
Myoepithelial carcinoma & Lymphoepithelial carcinoma \\
Oncocytic carcinoma & Metastasizing pleomorphic adenoma \\
Carcinoma ex pleomorphic adenoma (intracapsular/minimally invasive or with & Carcinoma ex pleomorphic adenoma (widely invasive or high \\
\multicolumn{1}{l}{ low grade histology) } & grade histology) \\
Sialoblastoma & Carcinosarcoma \\
Adenocarcinoma NOS and Cystadenocarcinoma, low grade & Adenocarcinoma and cystadenocarcinoma, NOS, high grade ${ }^{\text {a }}$ \\
\hline
\end{tabular}

${ }^{a}$ Intermediate grade variants of these tumors are controversial in the assignment of risk. For mucoepidermoid carcinoma this may depend on grading scheme used. For adenocarcinoma NOS, there is little data, but what is present suggests that intermediate grade should be placed in the high risk group

b Adenoid cystic carcinomas are all considered high risk in terms of local recurrence, but only solid adenoid cystic carcinoma (i.e. high pattern grade) is considered high risk for nodal metastasis

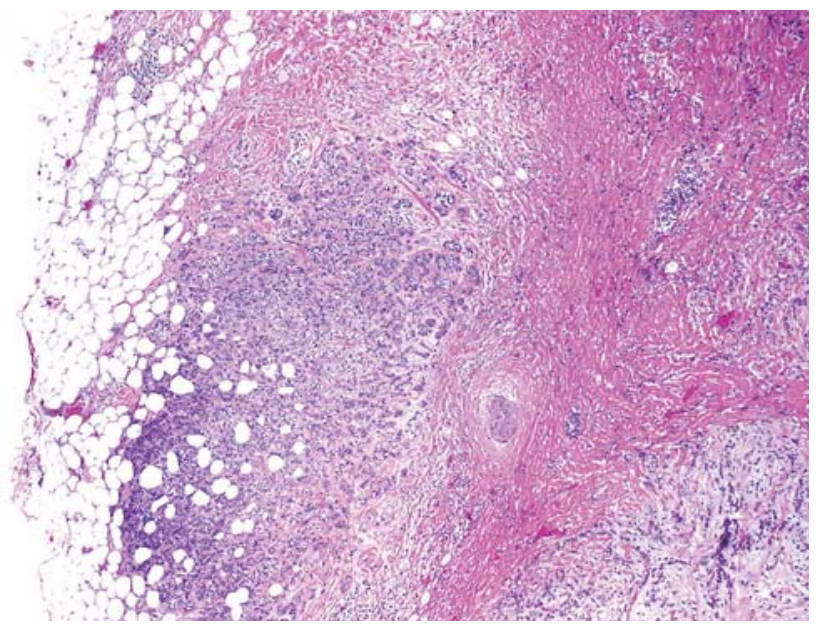

Fig. 1 Minimally invasive carcinoma ex pleomorphic adenoma. The pleomorphic adenoma component with sclerosis is seen on the right, and the minor low grade carcinoma component infiltrates the surrounding adipose tissue. This carcinoma was immunophenotypically a myoepithelial carcinoma (stains not shown)

Thus 'carcinoma ex pleomorphic adenoma' in current practice is not sufficient as a stand alone diagnosis. Recommendations for reporting on these tumors are:

- Histologic type/grade

- Percentage of carcinoma

- Extend of invasion of the carcinomatous component (intracapsular, minimally invasive, and invasive).

For more common malignancies however, grading systems have evolved and applied with some degree of efficacy. The two major named tumor types that are consistently graded in current practice are adenoid cystic carcinoma, and mucoepidermoid carcinoma. Additionally, adenocarcinoma NOS and cystadenocarcinoma, are also typically assigned a grade, though these tumors are not common enough to generate a formal system. Finally, grading of acinic cell carcinomas is somewhat controversial. Typically considered a 'low risk' tumor, many studies suggest an unusually high rate of lymph node metastasis as compared to other low risk tumors. Additionally histologic studies actually point to the ability to stratify these tumors based on cytomorphologic grading parameters $[6,7]$ suggesting that a grading system is necessary for these tumors.

\section{Adenoid Cystic Carcinoma}

Adenoid cystic carcinoma is a biphasic (composed of ducts and basal/myoepithelial cells) salivary gland malignancy characterized by tubular cribriform and or solid growth patterns. The biologic course of this tumor overall is slow but relentless- 5 year survival is favorable at roughly $75-80 \%$, but 15 year survival is poor at about $35 \%[8,9]$. Adenoid cystic carcinoma is unusual in that it is cytologically fairly monomorphic, yet locally quite aggressive placing it in a 'high risk' category with regard to the use of adjuvant radiation. In contrast, the likelihood of lymph node involvement may be as low as 5\%, and many institutions consider this tumor 'low risk' for lymph node metastases and thus do not perform neck dissection if clinicoradiographically node negative [3].

Grading of adenoid cystic carcinoma has been shown to be prognostically useful in several series [9-11]. Unlike 
many grading schemes, adenoid cystic carcinoma grading quick and simple in that it is based solely on growth pattern. As early as 1958, Patey and Thackray [12] noted that a solid growth pattern imparts a poor prognosis. Subsequently, grading of this tumor has evolved into stratification into three grades of increasing aggressiveness based on predominant growth pattern: $[10,11]$ grade 1 : tubular, grade 2: cribriform, grade 3: solid (Fig. 2). Generally, a tumor with a greater than $30 \%$ solid component belongs in the 'grade 3' category. However, it is suggested that any solid component imparts a poor prognosis, and that the relationship between solid growth pattern percentage and prognosis is somewhat linear and that assigning a cutoff may be arbitrary. The current WHO classification refers to tumors by predominant pattern rather than actually assigning a numeric grade.

One of the controversies surrounding grading of adenoid cystic carcinoma is its prognostic utility independent of tumor stage. Spiro et al. [8] suggest that this is not the case, however, more recently, da Cruz Perez et al. [13] show that grade is an independent prognosticator on multivariate analysis. One potential difference that the grading scheme used by Spiro et al. [8] differs from the typical scheme particularly with regards to a solid component cut-off of over $>50 \%$. The difficulties in conversion between the two grading schemes are illustrated in Table 3. Reproducibility of grading in adenoid cystic carcinoma has not been well addressed in the literature. In one study, [14] ironically, the grading system used by Spiro et al. [8] has less interobserver variability.

While prognostically useful, it is unclear whether grading of adenoid cystic carcinoma is useful in patient management. Regardless of grade, all adenoid cystic carcinomas are treated with surgery plus irradiation because locally they are aggressive and 'high risk'. With regard to the neck, most decisions on the neck dissection will not depend on grade, though there is some evidence to suggest that solid/grade 3 adenoid cystic carcinomas have a higher likelihood of lymph node metastasis [3]. With regards to this point, the rare phenomenon of dedifferentiation or high grade transformation may have
Table 3 Comparison of common pattern grading schemes in adenoid cystic carcinoma

\begin{tabular}{llll}
\hline Grade & $\begin{array}{l}\text { Perzin et al. [10], } \\
\text { Szanto et al. [11] }\end{array}$ & Grade & Spiro et al. [8] \\
\hline 1 & $\begin{array}{c}\text { Predominantly tubular, no } \\
\text { solid component }\end{array}$ & $\begin{array}{l}\text { Mostly tubular or } \\
\text { cribriform (no } \\
\text { stipulations on minor }\end{array}$ \\
2 & $\begin{array}{c}\text { Predominantly cribriform, } \\
\text { solid component }<30 \%\end{array}$ & solid components) \\
& acceptable & & $50 \%$ solid \\
3 & Solid component $>30 \%$ & 2 & Mostly solid \\
\hline
\end{tabular}

relevance. Adenoid cystic carcinoma with high grade transformation refers to the presence of a pleomorphic mitotically active high grade carcinoma component arising in an otherwise conventional adenoid cystic carcinoma of any pattern/grade (Fig. 3a) [15]. The transformed component is typically of a purely ductal phenotype with a solid or cribriform appearance. Unlike conventional adenoid cystic carcinoma, which is characterized by small, hyperchromatic, monomorphic nuclei, and scant cytoplasm, transformed components show prominent nuclear size and chromatin variability. Common features include fibrocellular desmoplasia, abundant mitoses, necrosis, and microcalcifications. Unique patterns in high grade transformation include micropapillary and squamoid growth. However, there is still morphologic overlap between solid conventional adenoid cystic carcinoma and high grade transformation and the transition from conventional adenoid cystic to high grade transformation is often gradual. Table 4 delineates key distinguishing features between solid conventional adenoid cystic carcinoma and adenoid cystic carcinoma with high grade transformation. Basically, the aggressive nuclear, stromal, architectural and immunohistochemical features common to both variants are more exaggerated in high grade transformation, while solid conventional adenoid cystic carcinoma shows only slight deviation from tubular or cribriform conventional adenoid cystic carcinoma.
Fig. 2 The various patterns/ grades of adenoid cystic carcinoma. a Tubular, b cribriform, c solid. All grades are cytologically monomorphic and retain small dark angulated nuclear features

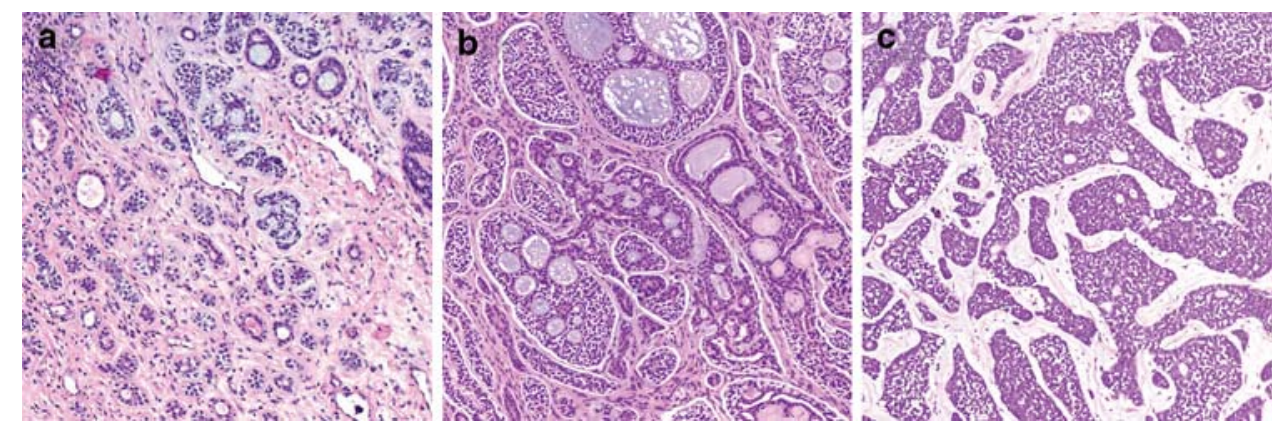


Fig. 3 Adenoid cystic carcinoma with high grade transformation.

a A conventional cribriform component with monomorphic nuclei on top transitions to a pleomorphic highly atypical adenocarcinoma on bottom. b The transformed component metastasized to a cervical lymph node

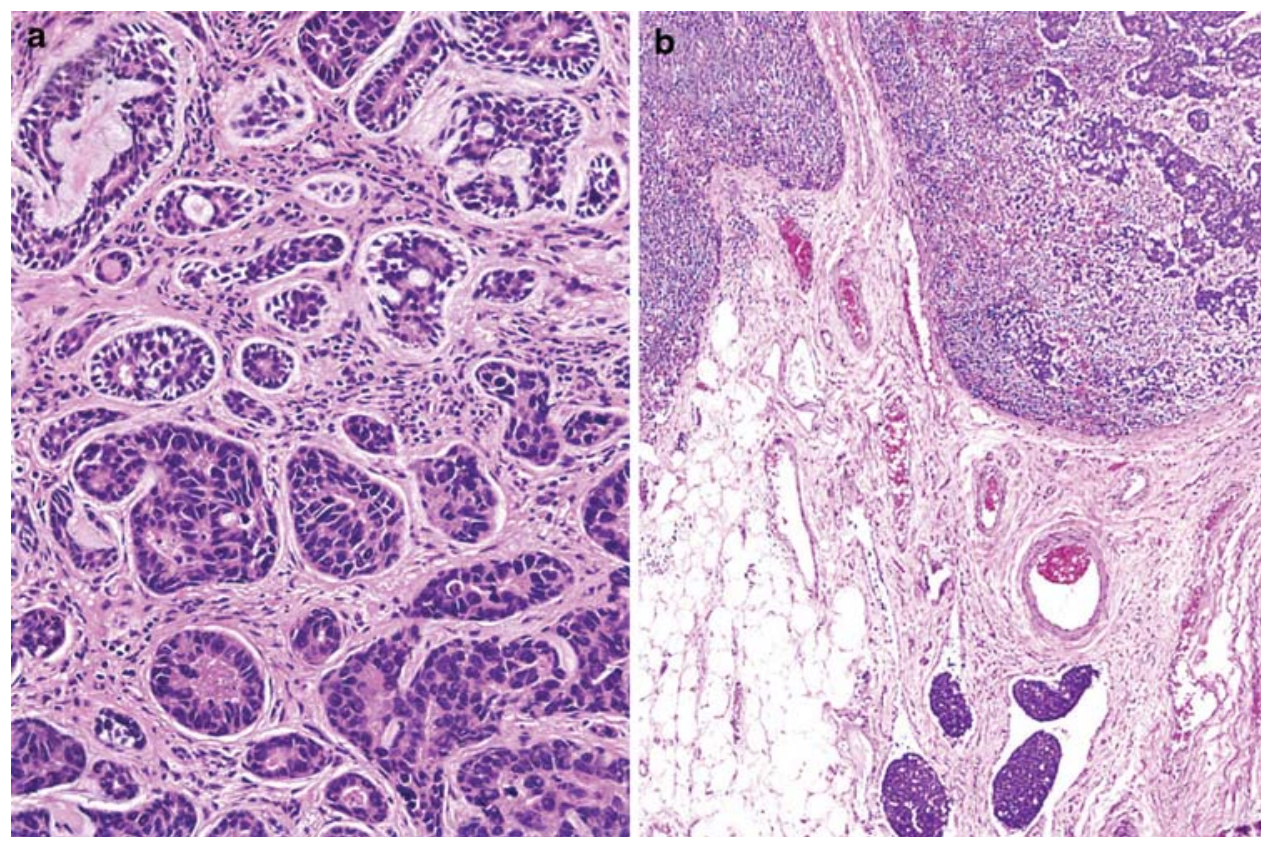

Table 4 Comparison of solid conventional adenoid cystic carcinoma and high grade transformation ${ }^{\mathrm{a}}$

\begin{tabular}{|c|c|c|}
\hline Features & Solid conventional adenoid cystic carcinoma & Adenoid cystic carcinoma with high grade transformation \\
\hline Chromatin & Dark, homogeneous & Vesicular or heterogeneously dispersed \\
\hline Nuclear membranes & Delicate & Thickened or irregular \\
\hline Nucleoli & Present but indistinct & Prominent central \\
\hline Nuclear size & $\begin{array}{l}\text { At most twice the size of grade I-II ACC } \\
\text { nuclei. Uniform size distribution }\end{array}$ & $\begin{array}{l}\text { At least } 2-3 \text { times the size of grade I-II ACC nuclei } \\
\text { (typically more). At least } 2 \text { fold nuclear variation }\end{array}$ \\
\hline Cytoplasm & Scant to nearly absent & Scant to moderate \\
\hline Growth & $\begin{array}{l}\text { Solid nests, rarely spanning more than a } \\
40 \times \text { high power field }\end{array}$ & $\begin{array}{l}\text { Solid confluent nests to sheets often filling a } 40 \times \text { high } \\
\text { power field }\end{array}$ \\
\hline Stroma & Paucicellular myxoid or hyaline & Fibrocellular desmoplastic \\
\hline Comedonecrosis & Focally present, usually punctuate & Often present, punctuate to large zones \\
\hline Microcalcifications & Rarely present & Often present \\
\hline Unique features & & Micropapillae, squamoid areas \\
\hline Mitoses & Generally $<10 / \mathrm{hpf}$ & Usually $>10 / \mathrm{hpf}$ \\
\hline $\begin{array}{l}\text { Abluminal cell layer presence } \\
\text { by immunohistochemistry }\end{array}$ & Present and complete & Incomplete and at least focally absent \\
\hline $\mathrm{Ki}-67$ & $<50 \%$ & $>50 \%$ \\
\hline $\begin{array}{l}\text { p53 overexpression (strong } \\
\text { reactivity in }>50 \% \text { of cells) }\end{array}$ & Rare & Common \\
\hline
\end{tabular}

Bold = Major Features

a Adapted from Seethala et al. [15]

These tumors have an exceptionally poor prognosis with a median survival ranging from 12 to 36 months, and may thus be even more aggressive that solid or 'grade 3' adenoid cystic carcinoma. Unlike conventional adenoid cystic carcinoma, this tumor has a lymph node metastatic rate of over 50\% (Fig. 3b). Thus if a transformed component is found in an adenoid cystic carcinoma, a neck dissection is likely warranted.
Summary recommendations for grading of adenoid cystic carcinoma:

- Report predominant growth pattern (tubular, cribriform, or solid)

- If any solid component is present give rough estimate of percentage 
- It may be reasonable to indicate in a comment that a solid component $>30 \%$ correlates with aggressive behavior.

- If evidence of high grade transformation is present, this should be reported and quantitated.

- A comment regarding the unusually high propensity for lymph node involvement is recommended.

\section{Mucoepidermoid Carcinoma}

Mucoepidermoid carcinoma is the most common salivary gland malignancy and is histologically comprised of a mixture of mucus cells, intermediate cells and squamoid or epidermoid cells. This tumor may also demonstrate clear cell, oncocytic or columnar cells. There is arguably no other salivary gland tumor in which grading is as important to prognosis and therapy. The reported overall 5 year survival for MEC ranges from 92 to $100 \%$ for low grade tumors, $62-92 \%$ for intermediate grade tumors, and $0-43 \%$ for high grade tumors [16]. A few recent studies have also highlighted the value of grade in the management of patients $[17,18]$. Low grade tumors generally require only surgical treatment, while high grade tumors require adjuvant radiation and neck dissection. The controversy arises in the management of intermediate grade mucoepidermoid carcinoma, and perhaps the root of this controversy lies within the grading system employed.

Even when described initially by Stewart et al. [19] in 1945, two types of mucoepidermoid carcinoma were documented, a 'benign' and 'malignant' version which equate today to low and high grade respectively. Shortly thereafter, the potential need for an intermediate category was recognized [20]. Today, mucoepidermoid are carcinoma graded by most using three tiers: low, intermediate and high grade. The three most popular grading systems are: the AFIP grading system [21], modified Healey system [22], and the Brandwein [23] system (Table 5). All categories assess a similar set of parameters, both

Table 5 Comparison of Grading Systems for Mucoepidermoid Carcinoma

\begin{tabular}{|c|c|c|}
\hline $\begin{array}{l}\text { Modified Healey [22] } \\
\text { Qualitative }\end{array}$ & $\begin{array}{l}\text { AFIP [21] } \\
\text { Point based }\end{array}$ & $\begin{array}{l}\text { Brandwein [23] } \\
\text { Point based }\end{array}$ \\
\hline Low grade & $\begin{array}{l}\text { Intracystic component } \\
\quad<20 \%=2 \mathrm{pts}\end{array}$ & $\begin{array}{l}\text { Intracystic component } \\
\quad<25 \%=2 \mathrm{pts}\end{array}$ \\
\hline Macrocysts, microcysts, transition with excretory ducts & $\begin{array}{l}\text { Neural invasion } \\
\text { present }=2 \text { pts }\end{array}$ & $\begin{array}{l}\text { Tumor invades in small nests } \\
\quad \text { and islands }=2 \mathrm{pts}\end{array}$ \\
\hline $\begin{array}{l}\text { Differentiated Mucin producing Epidermoid Cells, often in a 1:1 } \\
\text { ration; minimal to moderate intermediate cell population }\end{array}$ & $\begin{array}{l}\text { Necrosis } \\
\text { present }=3 \text { pts }\end{array}$ & $\begin{array}{l}\text { Pronounced nuclear } \\
\quad \text { atypia }=2 \text { pts }\end{array}$ \\
\hline \multicolumn{3}{|l|}{ Daughter cyst proliferation from large cysts } \\
\hline \multicolumn{3}{|l|}{ Minimal to absent pleomorphism, rare mitoses } \\
\hline \multicolumn{3}{|l|}{ Broad-front, often circumscribed invasion } \\
\hline \multicolumn{3}{|l|}{ Pools of extravasated mucin with stromal reaction } \\
\hline Intermediate grade & $\begin{array}{l}\text { Mitosis }(4 \text { or more per } \\
10 \mathrm{HPF})=3 \mathrm{pts}\end{array}$ & $\begin{array}{l}\text { Lymphatic and/or vascular } \\
\quad \text { invasion }=3 \text { pts }\end{array}$ \\
\hline No macrocysts, few microcysts, solid nests of cells & Anaplasia $=4$ pts & Bony invasion $=3 \mathrm{pts}$ \\
\hline Large duct not conspicuous & & $>4$ mitoses per $10 \mathrm{HPF}=3 \mathrm{pts}$ \\
\hline \multicolumn{3}{|l|}{ Slight to moderate pleomorphism, few mitoses, prominent nuclei and nucleoli } \\
\hline \multicolumn{3}{|l|}{ Invasive quality, usually well difined and uncircumscribed } \\
\hline \multicolumn{3}{|l|}{$\begin{array}{l}\text { Chronic inflammation at periphery, fibrosis separates nests of cells and } \\
\text { groups of nests }\end{array}$} \\
\hline \multirow{3}{*}{\multicolumn{3}{|c|}{$\begin{array}{l}\text { High grade } \\
\text { No macrocysts, predominantly solid but may be nearly all glandular } \\
\text { Cell constituents range from poorly differentiated to recognizable epidermoid and } \\
\text { intermediate to ductal type adenocarcinoma }\end{array}$}} \\
\hline & & \\
\hline & & \\
\hline \multicolumn{3}{|l|}{ Considerable pleomorphism, easily found mitoses } \\
\hline \multicolumn{3}{|l|}{ Unquestionable soft tissue, perineural and intravascular invasion } \\
\hline \multirow{3}{*}{$\begin{array}{l}\text { Chronic inflammation less prominent, desmoplasia of stroma may outline invasive } \\
\text { clusters }\end{array}$} & Low grade $=0-4 \mathrm{pts}$ & Low grade $=0$ pts \\
\hline & $\begin{array}{l}\text { Intermediate } \\
\quad \text { grade }=5-6 \text { pts }\end{array}$ & Intermediate grade $=2-3 \mathrm{pts}$ \\
\hline & High grade $=7-14 \mathrm{pts}$ & High grade $=4$ or more pts \\
\hline
\end{tabular}


cytomorphologic and architectural, and may also include perineural and angiolymphatic invasion. Both the AFIP and Brandwein system are point based, assigning point values to each adverse histologic parameters and with ascending point scores equating to a higher grade. The modified Healey system can be considered a 'best fit' type system: certain histologic parameters characterize a particular grade, and a tumor is graded based on its predominant morphologic features.

Grading of mucoepidermoid carcinoma is not without flaws. One clear deficiency in all systems, particularly the point based schemes, the difficulty in application. Grading under these systems is a cumbersome and time consuming activity, and many of the criteria are not at all well-defined. In fact, based on personal experience, if asked, most pathologists tend not to use a formal system because of the time commitment and lack of 'user friendliness.' However, evidence suggests that the reproducibility of an informal or personal grading scheme is lower than when a standard grading scheme is used [23, 24] (Fig. 4).

Given an adequate sample size, all systems appear to be prognostically useful even independent of stage. However, the way in which each system correlates with outcome varies. The AFIP system appears to 'down grade' tumors while the Brandwein system appears to 'upgrade' tumors [24]. While these differences appear minor prognostically, therapeutically they have significant implications. The clinical expectation of a low grade mucoepidermoid carcinoma is that it is a 'low risk' tumor that is almost always cured by surgery alone and has a negligible lymph node metastatic rate. Here the danger of the AFIP system is potentially placing biologically more aggressive tumors into this low grade category increasing the failure rate of low grade tumors. Conversely, high grade mucoepidermoid carcinomas are aggressive tumors requiring adjuvant treatment and neck dissection. The concern with the Brandwein system is that it may place some indolent tumors in this high risk category, in which case some patients may receive unnecessary radiation or additional surgery.

The differences in grading schemes are amplified particularly with respect to intermediate grade tumors. There does not appear to be a clear cut answer on the management of patients in this category, but the few studies addressing this question on a single institution yield varying results. Aro et al. [17] using the AFIP system suggest that intermediate grade mucoepidermoid carcinoma cluster with high grade mucoepidermoid carcinoma, and should be treated in a similar fashion. However, Nance et al. [18] showed that intermediate grade mucoepidermoid carcinoma cluster with low grade mucoepidermoid carcinoma using the Brandwein system. Based on limited experience, the Healey system does not seem to have either of these limitations, but since intermediate grade tumors using this system literally behave in a fashion that is 'intermediate' to low and high grade, management may be even more ambiguous than with the other systems.

Finally, variants of mucoepidermoid carcinoma such as oncocytic or sclerosing variants may not be amenable to conventional grading schemes. Limited evidence to date suggests that even oncocytic mucoepidermoid carcinomas that are considered high grade (Fig. 5) by a conventional grading scheme may behave indolently, with only one recurrence noted [25]. However, evidence is still insufficient to make a firm recommendation to discard grading for these variants.

Thus current recommendations for grading mucoepidermoid carcinomas are:

- Utilize a standard scheme, rather than an 'intuitive' approach. (As a more streamlined well defined system
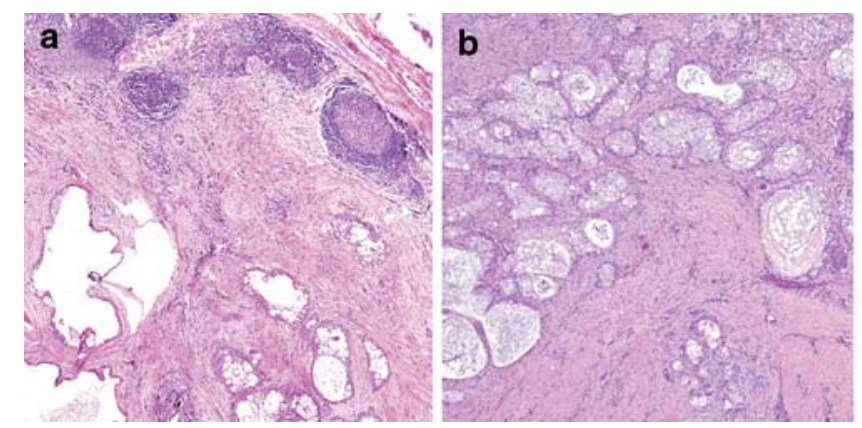

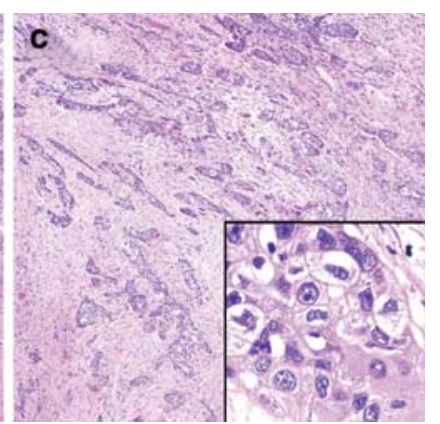

Fig. 4 Grading of mucoepidermoid carcinoma. a A low grade tumor demonstrating a well demarcated border, macrocystic spaces and a bland cyst lining. b An intermediate grade tumor demonstrating a more solid growth with only few microcysts, and focal infiltration. It is important to note that the Brandwein system may potentially classify this tumor as high grade (infiltration if these nests are considered 'small enough', and intracystic component $<25 \%$ equates to 4 points), while the AFIP grading system still categorizes this tumor as low grade (score is only 2/14). c High grade mucoepidermoid carcinoma with no cystic spaces and a highly infiltrative growth pattern. Inset: showing anaplasia or pronounced nuclear atypia 
Fig. 5 Oncocytic mucoepidermoid carcinoma. a This solid highly infiltrative oncocytic lesion would be classified in some grading schemes as high grade. $\mathbf{b}$ The tumor cells have abundant granular eosinophilic cytoplasm. c Only rare foci with mucus cells are noted. This patient suffered one recurrence 8 years after diagnosis but is currently free of disease for almost 5 years
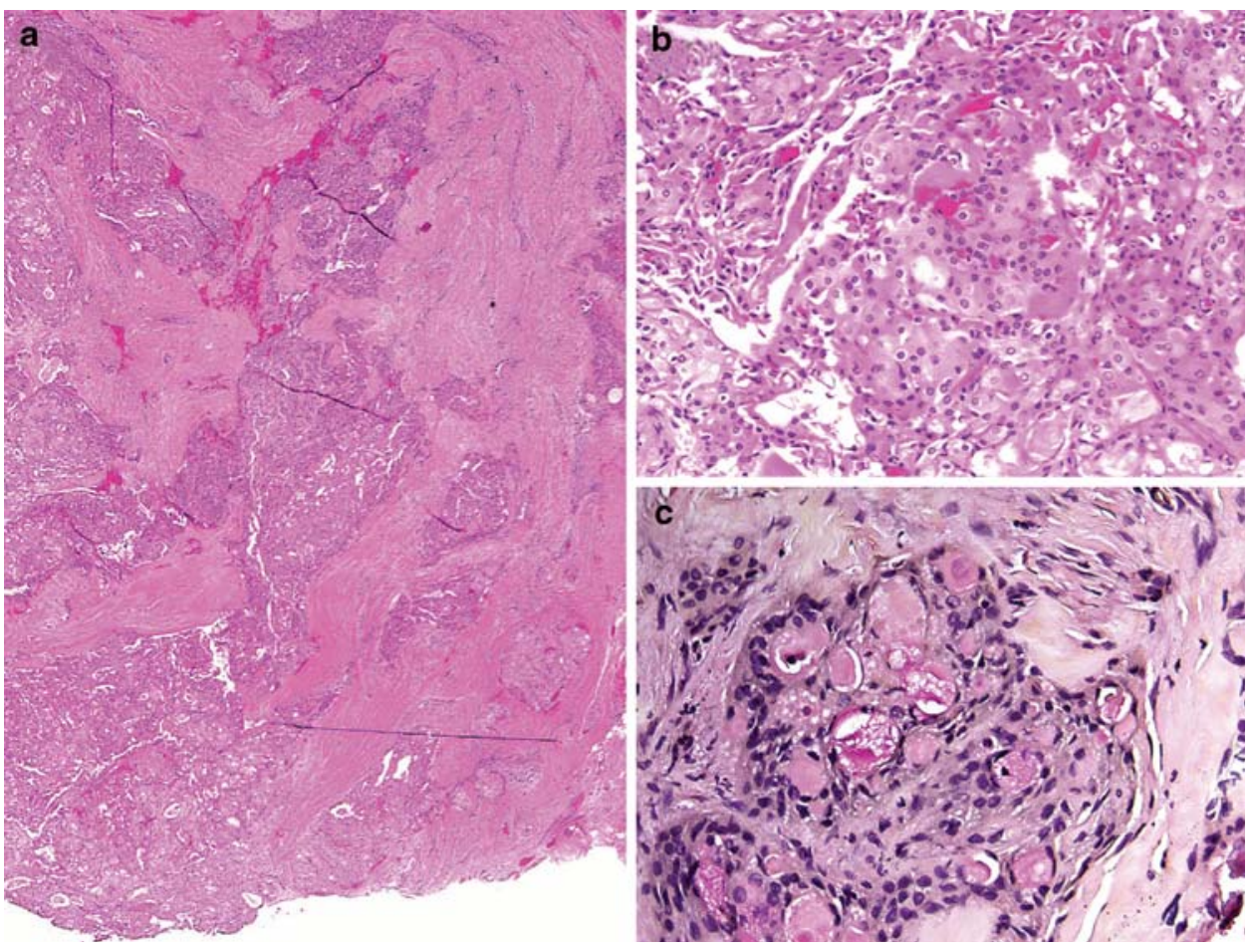

evolves that still retains predictive value, this notion may become more palatable).

- Regarding which system to use, understanding of the clinical expectations is necessary. In most practices in the United States, it is less acceptable for a low grade tumor to behave in an aggressive fashion than for a high grade tumor to behave indolently and possibly get overtreatment. Thus, the utilization of the Brandwein system or Healey system is preferable.

- Variants should still be graded in a similar fashion although limited evidence suggests that some variants may behave more indolently even if technically high grade.

\section{Conclusions}

Though histologic grading of salivary gland carcinomas is somewhat flawed, it does have prognostic value. Carcinoma ex pleomorphic adenoma should no longer be considered a specific diagnosis, but rather, a category in which the carcinoma should be typed, graded and quantitated to impart more prognostically and therapeutically relevant data. The two tumor types for which specific grading systems have evolved are adenoid cystic carcinoma and mucoepidermoid carcinoma. Adenoid cystic carcinoma is graded based on growth pattern with solid growth imparting a poorer prognosis. Rarely, these tumors will undergo high grade transformation in which case the tumor will have a much higher predilection for lymph node metastases than a conventional adenoid cystic carcinoma. In mucoepidermoid carcinomas, standardized grading systems are more reproducible than generic grade assignment, but in their current form, they are cumbersome and time consuming. The outcome in the intermediate grade category is heavily dependent on the grading system used and is thus the most controversial with regards to management and prognosis. The AFIP system downgrades tumors leading to aggressive behavior in the intermediate grade category while the Brandwein system upgrades tumors resulting in indolent behavior.

\section{References}

1. Eveson JW, Auclair PL, Gnepp DR, et al. Tumors of the salivary glands: introduction. In: Barnes EL, Eveson JW, Reichart P, Sidransky D, editors. World Health Organization classification of tumours: pathology \& genetics. Head and neck tumours. Lyon: IARCPress; 2005. p. 221-2.

2. Bell RB, Dierks EJ, Homer L, et al. Management and outcome of patients with malignant salivary gland tumors. J Oral Maxillofac Surg. 2005;63(7):917-28.

3. Myers EN, Ferris RL, editors. Salivary gland disorders. Berlin: Springer; 2007.

4. Lima RA, Tavares MR, Dias FL, et al. Clinical prognostic factors in malignant parotid gland tumors. Otolaryngol Head Neck Surg. 2005; 133(5):702-8.

5. Lewis JE, Olsen KD, Sebo TJ. Carcinoma ex pleomorphic adenoma: pathologic analysis of 73 cases. Hum Pathol. 2001;32(6): 596-604.

6. Lewis JE, Olsen KD, Weiland LH. Acinic cell carcinoma. Clinicopathologic review. Cancer. 1991;67(1):172-9. 
7. Michal M, Skalova A, Simpson RH, et al. Well-differentiated acinic cell carcinoma of salivary glands associated with lymphoid stroma. Hum Pathol. 1997;28(5):595-600.

8. Spiro RH, Huvos AG. Stage means more than grade in adenoid cystic carcinoma. Am J Surg. 1992;164(6):623-8.

9. Fordice J, Kershaw C, El-Naggar A, et al. Adenoid cystic carcinoma of the head and neck: predictors of morbidity and mortality. Arch Otolaryngol Head Neck Surg. 1999;125(2):149-52.

10. Perzin KH, Gullane P, Clairmont AC. Adenoid cystic carcinomas arising in salivary glands: a correlation of histologic features and clinical course. Cancer. 1978;42(1):265-82.

11. Szanto PA, Luna MA, Tortoledo ME, et al. Histologic grading of adenoid cystic carcinoma of the salivary glands. Cancer. 1984;54(6):1062-9.

12. Patey DH, Thackray AC. The treatment of parotid tumours in the light of a pathological study of parotidectomy material. Br J Surg. 1958;45(193):477-87.

13. da Cruz Perez DE, de Abreu Alves F, Nobuko Nishimoto I, et al. Prognostic factors in head and neck adenoid cystic carcinoma. Oral Oncol. 2006;64(11):1592-97.

14. Therkildsen MH, Reibel J, Schiodt T. Observer variability in histological malignancy grading of adenoid cystic carcinomas. APMIS. 1997;105(7):559-65.

15. Seethala RR, Hunt JL, Baloch ZW, et al. Adenoid cystic carcinoma with high-grade transformation: a report of 11 cases and a review of the literature. Am J Surg Pathol. 2007;31(11):1683-94.

16. Ellis G, Auclair P, editors. Tumors of the salivary glands. Atlas of tumor pathology. No. 17, 3rd Series ed. Washington DC: Armed Forces Institute of Pathology; 1996.
17. Aro K, Leivo I, Makitie AA. Management and outcome of patients with mucoepidermoid carcinoma of major salivary gland origin: a single institution's 30-year experience. Laryngoscope. 2008;118(2):258-62.

18. Nance MA, Seethala RR, Wang Y, et al. Treatment and survival outcomes based on histologic grading in patients with head and neck mucoepidermoid carcinoma. Cancer. 2008;113(8):2082-9.

19. Stewart FW, Foote FW, Becker WF. Mucoepidermoid tumors of salivary glands. Ann Surg. 1945;122:820-44.

20. Foote FW Jr, Frazell EL. Tumors of the major salivary glands. Cancer. 1953;6(6):1065-133.

21. Goode RK, Auclair PL, Ellis GL. Mucoepidermoid carcinoma of the major salivary glands: clinical and histopathologic analysis of 234 cases with evaluation of grading criteria. Cancer. 1998; 82(7):1217-24.

22. Batsakis JG, Luna MA. Histopathologic grading of salivary gland neoplasms: I mucoepidermoid carcinomas. Ann Otol Rhinol Laryngol. 1990;99(10 Pt 1):835-8.

23. Brandwein MS, Ferlito A, Bradley PJ, et al. Diagnosis and classification of salivary neoplasms: pathologic challenges and relevance to clinical outcomes. Acta Otolaryngol. 2002; 122(7):758-64.

24. Seethala RR, Hoschar AP, Bennett A, et al. Reproducibility of grading in salivary gland mucoepidermoid carcinoma and correlation with outcome: does system really matter? Mod Pathol. 2008;21(S1):241A.

25. Weinreb I, Seethala RR, Perez-Ordonez B, et al. Oncocytic mucoepidermoid carcinoma: clinicopathologic description in a series of 12 cases. Am J Surg Pathol. Oct 282008 [Epub ahead of print]. 